\title{
BMJ Open Cross-sectional survey on defensive practices and defensive behaviours among Israeli psychiatrists
}

\author{
I Reuveni, ${ }^{1}$ I Pelov, ${ }^{1}$ H Reuveni, ${ }^{2}$ O Bonne, ${ }^{1}$ L Canetti ${ }^{1,3}$
}

To cite: Reuveni I, Pelov I, Reuveni $\mathrm{H}$, et al. Crosssectional survey on defensive practices and defensive behaviours among Israeli psychiatrists. BMJ Open 2017;7:e014153. doi:10.1136/bmjopen-2016014153

- Prepublication history and additional material is available. To view please visit the journal (http://dx.doi.org/ 10.1136/bmjopen-2016014153).

IR and IP contributed equally to this article.

Received 11 September 2016 Revised 17 January 2017 Accepted 8 February 2017

CrossMark

For numbered affiliations see end of article.

Correspondence to Dr I Reuveni; reuveni@ hadassah.org.il

\section{ABSTRACT}

Objective: Psychiatry is a low-risk specialisation; however, there is a steady increase in malpractice claims against psychiatrists. Defensive psychiatry (DP) refers to any action undertaken by a psychiatrist to avoid malpractice liability that is not for the sole benefit of the patient's mental health and well-being. The objectives of this study were to assess the scope of DP practised by psychiatrists and to understand whether awareness of DP correlated with defensive behaviours. Methods: A questionnaire was administered to 213 Israeli psychiatry residents and certified psychiatrists during May and June 2015 regarding demographic data and experience with malpractice claims, medicolegal literature and litigation. Four clinical scenarios represented defensive behaviours and reactions (feelings and actions) to malpractice claims.

Results: Forty-four (20.6\%) certified psychiatrists and four $(1.9 \%)$ residents were directly involved in malpractice claims, while $132(62.1 \%)$ participants admitted to practising DP. Residents acknowledged the practice of DP more than did senior psychiatrists $(p=0.038)$.

Awareness of DP correlated with unnecessary hospitalisation of suicidal patients, increased unnecessary follow-up visits and prescribing smaller drug dosages than required for pregnant women and elderly patients.

Conclusions: This study provides evidence that DP is well established in the routine clinical daily practice of psychiatrists. Further studies are needed to reveal whether DP effectively protects psychiatrists from malpractice suits or, rather, if it impedes providing quality psychiatric care and represents an economic burden that leads to more harm for the patient.

\section{INTRODUCTION}

Defensive medicine comprises medical actions that deviate from sound medical practice, performed primarily to reduce exposure to malpractice liability or to provide legal protection in the case of a malpractice lawsuit. ${ }^{1-3}$ Defensive psychiatry (DP) refers to any action undertaken by a psychiatrist mainly to avoid malpractice liability, rather

\section{Strengths and limitations of this study}

- This is the first survey among Israeli psychiatrists to assess the scope of defensive practices and behaviours carried out in the public and private sectors.

- Defensives practices were assessed in four clinical domains (suicidal, pregnant and elderly patients, and medication initiation/change) to target major issues in the field of psychiatry liable to medicolegal actions.

- The study identified specific actions taken by psychiatrists to avoid malpractice liability.

- Psychiatrists' perceptions of defensive medicine, contrary to objective data, may be biased and lead physicians to overstate the frequency of performing defensive medicine.

than for the sole benefit of the patient's mental health and well-being. ${ }^{4}$ There are two main forms of defensive medical behaviours described in the literature: (1) Assurance behaviour ('positive defensive medicine'), which involves ordering diagnostic tests and/ or treatments, referrals to other physicians and additional services of marginal medical value merely to prevent or limit liability. An example in psychiatry would be a patient with suicidal ideation who could and should be treated as an outpatient, but is hospitalised merely for defensive reasons. (2) Avoidance behaviour ('negative defensive medicine') refers to the physician's reluctance to be involved in the treatment of high-risk patients or procedures. ${ }^{2} 4$ An example of this is the reluctance to prescribe medication to pregnant women suffering from affective or anxiety disorders, although there are clear indications to begin pharmacological treatment.

The practice of defensive medicine places a great economic burden on society; in addition, it is not supported by evidence-based studies and can be harmful due to complications from unnecessary tests and procedures. $^{1} 3^{3} 5_{-7}$ Various studies have tried to 
evaluate the cost of defensive medicine over the years. Kessler and McClellan ${ }^{5}$ showed that defensive medicine is responsible for up to $9 \%$ of total health spending. Others showed lower percentages (around $1.5 \%$ of the total health expenditure). Mello and colleagues ${ }^{6}$ estimated the total annual cost of medical liability in 2008 to be more than 55 billion dollars in the USA. Nonetheless, it is a widespread phenomenon rooted in various fields of medicine. Studdert et at showed that up to $93 \%$ of physicians in a high-risk environment practise defensive medicine. Asher $e t a l^{3}$ demonstrated, in a nationwide survey in Israel, that defensive behaviours are common (up to $60 \%$ prevalence) in eight medical disciplines, four of which are not considered to be at high risk for litigation. Another study showed that $97 \%$ of obstetricians and gynaecologists felt that their daily work practice was affected by concerns about being sued for medical negligence. ${ }^{8}$

Psychiatry is considered a low-risk specialisation. ${ }^{9} 10$ However, data from recent years demonstrated that there is a steady increase in reports of medical negligence, claims of malpractice and reports at the state board level against psychiatrists. ${ }^{41}$ Some of the allegations made in litigation cases in the field of psychiatry include incorrect diagnosis, incorrect or ineffective treatment, medication errors, improper detention while hospitalised, doctor-patient boundary violations and inadequate assessment and management of suicidal patients. ${ }^{4} 1012$ Research regarding DP is scarce and mostly limited to suicide assessments.

\section{Aims of study}

The primary aim of this study was to assess the scope of defensive medicine practised by Israeli psychiatrists in the public and private sectors. The secondary aim was to understand how one's awareness of defensive practices correlates with applying defensive behaviours and the psychological impact of past malpractice claims.

\section{METHODS}

Two hundred and thirteen Israeli certified psychiatrists and residents in psychiatry volunteered to complete a cross-sectional survey on defensive practices and attitudes. This study was approved by the Israel Psychiatric Association and was administered during the Triannual Congress of the Israel Psychiatric Association in May 2015. The survey was completely anonymous and included an introduction with an explanation regarding the nature of the survey and definition for defensive medicine. There is only one previous questionnaire of defensive medicine in the psychiatric literature, reported by Passmore and Leung; ${ }^{13}$ therefore, we started with a replication of the previous questionnaire and added more details to examine the scope of DP as well as its application. Our research team consulted with experienced psychiatrists holding academic positions in university medical centres on important topics in the field in order to develop the questionnaire. It was pretested on 17 psychiatry residents (mean age $=33.8, \quad \mathrm{SD}=3.6$ ) working in public hospitals, who volunteered to participate in the survey. Following the pretest, minor changes were made according to the research team's suggestions. The survey took $\sim 10 \mathrm{~min}$ to complete.

The final questionnaire asked about demographic data (age, gender, professional position within department, work experience and work in public and private practices) as well as personal experience with malpractice claims and exposure to medicolegal literature and litigation. To survey the extent of defensive medicine, we asked a direct question: 'Do you practice defensive medicine?' Admission of practising defensive medicine with at least half of the physician's patients was considered as acknowledgment of defensive medicine by the participant. In addition, we asked participants about defensive behaviours in various clinical scenarios. Specifically, we inquired about 13 behaviours in four domains (see online supplementary material). These domains were chosen by our research team to target major issues in the field of psychiatry and day-to-day practice, as well as high-risk cases for medicolegal actions. The four scenarios of possible defensive practice were: (1) treatment of suicidal patients, (2) treatment of pregnant women, (3) initiating or changing drug treatment and (4) treatment of elderly patients. Participants scored the practice of specific defensive behaviours on a 5-point Likert scale as follows: 5 'with every patient', 4 'with most patients', 3 'with half of the patients', 2 'with a few patients' and 1 'with no patient'. To assess the internal reliability, we calculated Cronbach's $\alpha$ of the 13 items that measured defensive behaviours, resulting in good internal consistency: $\alpha=0.67$. Participants were also asked about their feelings (anxious, restless, angry, loss of energy or tired, guilty and mistrustful) and functioning (sleep problems and interference with work, family or social activities) in the period they were involved in malpractice claims.

\section{Statistical analysis}

Continuous data were analysed using the t-test for independent samples or Pearson correlation coefficients. Reported $\mathrm{p}$ values are two-sided. All analyses were performed using the IBM SPSS V.21.0 (IBM Corp, 2012) statistical software.

\section{RESULTS}

The demographic characteristics of the psychiatrists surveyed are presented in table 1 . In our sample, both sexes were almost equally represented; about threequarters were certified psychiatrists and slightly less than half were in a management position. Most participants $(77.9 \%)$ worked in a public hospital and more than half $(53.5 \%)$ had a private practice. Of the 213 psychiatrists, only 48 (22\%) were directly involved in malpractice claims. Among them, $44(91.7 \%)$ were certified psychiatrists and four $(8.3 \%)$ were residents. 
Table 1 Demographic characteristics of the sample of Israeli psychiatrists

\begin{tabular}{lr}
\hline Age & M=48.00 (SD=11.82) \\
\hline Gender & \\
Male & $117(54.9 \%)$ \\
Female & $96(45.1 \%)$ \\
Experience & \\
Resident & $44(20.7 \%)$ \\
Certified & $169(79.3 \%)$ \\
Department position & \\
Resident & $44(20.7 \%)$ \\
Consultant & $67(31.4 \%)$ \\
Department head & $102(47.9 \%)$ \\
Place of work & $166(77.9 \%)$ \\
Public hospital & $41(19.2 \%)$ \\
HMO & $114(53.5 \%)$ \\
Private practice & \\
History of malpractice claims & $48(22.5 \%)$ \\
Yes & $165(77.5 \%)$ \\
No & $104(48.8 \%)$ \\
Reading medicolegal literature and litigation \\
Yes & $109(51.2 \%)$ \\
No &
\end{tabular}

There was a small but significant negative correlation between the age of the participants and acknowledgement of defensive practice $(\mathrm{r}=-0.14, \mathrm{p}=0.049)$, meaning that there is a tendency in younger participants to admit that they practise defensive medicine. In treating suicidal patients, female psychiatrists were more prone to consult with a senior psychiatrist than male practitioners (female psychiatrists: $\mathrm{M}=3.41, \mathrm{SD}=1.27$; male psychiatrists: $\left.\mathrm{M}=2.85, M=1.20 ; \mathrm{t}_{(171)}=-2.96 ; \mathrm{p}=0.004\right)$ and more prone to refer to another mental health professional (female psychiatrists: $\mathrm{M}=3.28, \mathrm{SD}=0.87$; male psychiatrists: $\left.\mathrm{M}=2.90, \mathrm{SD}=1.13 ; \mathrm{t}_{(180)}=-2.59 ; \mathrm{p}=0.010\right)$. There were no significant differences in the acknowledgement or practice of defensive medicine when examining the department position, place of work or reading medicolegal literature. Participants reporting a history of malpractice claims were more prone to acknowledge defensive practice $(\mathrm{M}=3.02, \mathrm{SD}=0.96)$ compared with those who did not $(\mathrm{M}=2.60, \mathrm{SD}=0.85)$ and this difference was significant $\left(\mathrm{t}_{(192)}=2.82 ; \mathrm{p}=0.005\right)$.

There were significant differences between residents in psychiatry and certified psychiatrists for the practice of defensive medicine (table 2). Residents acknowledged the practice of defensive medicine more than did experienced psychiatrists $(p=0.038)$. For suicidal patients, residents were more prone to advise hospitalisation $(p=0.017)$ and to consult with senior psychiatrists $(p<0.001)$ than certified psychiatrists. Residents avoided the prescription of drugs to pregnant patients more than did experienced psychiatrists $(p=0.025)$. For elderly patients treated with antipsychotics, certified psychiatrists explained the risks of cerebrovascular diseases more than did residents $(\mathrm{p}=0.009)$.
In our sample, $62.1 \%$ of participants admitted practising defensive medicine with at least half of their patients (table 3), and this was very common in all four surveyed domains. To understand the relationship between acknowledging defensive practice and actually practising defensive medicine, we computed the correlation between the answer to 'Do you practice defensive medicine?' and self-reports of defensive practice behaviours in the four clinical scenarios mentioned above. As shown in table 3, participants felt they were employing defensive procedures when treating suicidal patients when they advised hospitalisation, even if not necessary, or increased the frequency of follow-up visits when not warranted. They also felt that they were practising defensive medicine when prescribing smaller drug dosages than required in the treatment of pregnant women and elderly patients. Other behaviours, even if very frequent, were apparently not considered defensive medicine by our subjects; thus, they did not correlate with the acknowledgement of defensive practice.

Of the 58 participants who reported how they were affected by malpractice claims, 36 felt anxious, 33 angry, 26 restless, 16 distrustful, 14 guilty, while 14 reported loss of energy or fatigue, 16 had sleeping problems and 11 reported impaired functioning in work, family relations or social activities. Since anxiety and anger were the most reported psychological symptoms, we further calculated Pearson correlation coefficients between levels of anxiety or anger and measures of defensive behaviour and defensive practice. We found positive associations between the level of anxiety and acknowledging defensive practice, advising hospitalisation in suicidal patients, and avoiding drug prescription in suicidal patients. We also found an almost significant trend between levels of anxiety and increased follow-up in suicidal patients and telling the patient about increased suicidal symptoms before starting selective serotonin reuptake inhibitors (table 3). The only significant correlation with anger was advising hospitalisation in suicidal patients $(\mathrm{r}=0.37$ $\mathrm{p}=0.006)$.

\section{DISCUSSION}

This is the first study to describe defensive medicine among psychiatrists that reports on the extent of the phenomenon as well as identifies specific actions taken by psychiatrists to avoid malpractice liability.

This study demonstrates that defensive medicine is a well-rooted common practice among psychiatrists as the prevalence of defensive medicine was $62.1 \%$. These results are similar to a prior study conducted among psychiatrists in the UK, focusing on four specified actions: admitting patients to the hospital when their condition could be managed as an outpatient, placing patients on a higher level of observation than warranted, writing in patients' records specific remarks such as 'not suicidal' and dictating letters more than necessary for managing the patient's illness. Overall, three-quarters of 
Table 2 Defensive medicine: comparison between residents and certified psychiatrists

\begin{tabular}{|c|c|c|c|c|c|}
\hline & $\begin{array}{l}\text { Certified } \\
\text { M (SD) }\end{array}$ & $\begin{array}{l}\text { Resident } \\
\text { M (SD) }\end{array}$ & $\mathbf{t}$ & df & p Value \\
\hline $\begin{array}{l}\text { Acknowledgement of defensive practice } \\
\text { Defensive behaviours }\end{array}$ & $2.62(0.93)$ & $2.90(0.73)$ & 2.11 & 196 & 0.038 \\
\hline \multicolumn{6}{|l|}{ Suicidal patients } \\
\hline Advises unwarranted hospitalisation & $2.82(1.09)$ & $3.34(1.28)$ & 2.46 & 199 & 0.017 \\
\hline Increases follow-up & $3.51(1.10)$ & $3.75(1.04)$ & 1.30 & 199 & 0.195 \\
\hline Initiates contact with family & $4.05(0.83)$ & $3.96(0.87)$ & -0.51 & 178 & 0.611 \\
\hline Consults senior psychiatrist & $2.84(1.14)$ & $4.62(0.75)$ & 10.16 & 171 & $<0.001$ \\
\hline Refers to another professional & $3.03(1.03)$ & $3.35(1.06)$ & 1.47 & 180 & 0.144 \\
\hline Prescribes medication without indication & $1.71(0.72)$ & $2.00(0.89)$ & 1.83 & 180 & 0.069 \\
\hline \multicolumn{6}{|l|}{ Changing or initiating new medication } \\
\hline Informs about severe yet rare side effects & $3.45(1.29)$ & $3.30(1.27)$ & -0.69 & 208 & 0.490 \\
\hline Records that explained about side effects & $3.49(1.25)$ & $3.27(1.28)$ & -1.02 & 207 & 0.308 \\
\hline Informs of increased risk of suicidality & $2.74(1.44)$ & $2.52(1.37)$ & -0.88 & 205 & 0.380 \\
\hline \multicolumn{6}{|l|}{ Pregnant patients } \\
\hline Avoids medication altogether & $2.56(1.04)$ & $3.09(1.08)$ & 2.25 & 186 & 0.025 \\
\hline Prescribes a smaller dosage & $2.44(1.21)$ & $2.46(1.25)$ & 0.062 & 191 & 0.950 \\
\hline \multicolumn{6}{|l|}{ Elderly patients } \\
\hline Informs of cerebrovascular diseases risk & $3.00(1.30)$ & $2.37(1.38)$ & -2.65 & 191 & 0.009 \\
\hline Prescribes a smaller dosage & $3.95(0.93)$ & $3.95(0.66)$ & -0.02 & 195 & 0.986 \\
\hline
\end{tabular}

Table 3 Defensive medicine: frequencies and correlations with acknowledgement of defensive practice and with anxiety

\begin{tabular}{|c|c|c|c|}
\hline & $\begin{array}{l}\text { Per cent of defensive } \\
\text { practice or behaviours }\end{array}$ & $\begin{array}{l}\text { Correlation with } \\
\text { acknowledgement of } \\
\text { defensive practice }\end{array}$ & $\begin{array}{l}\text { Correlation } \\
\text { with anxiety }\end{array}$ \\
\hline $\begin{array}{l}\text { Acknowledgement of defensive practice } \\
\text { Defensive behaviours }\end{array}$ & $62.1 \%$ & 1.00 & $0.30^{*}$ \\
\hline \multicolumn{4}{|l|}{ Suicidal patients } \\
\hline Advises unwarranted hospitalisation & $54.2 \%$ & $0.34 \dagger$ & $0.47 \dagger$ \\
\hline Increases follow-up & $75.6 \%$ & $0.23 \dagger$ & $0.25 \ddagger$ \\
\hline Initiates contact with family & $93.3 \%$ & -0.11 & 0.10 \\
\hline Consults senior psychiatrist & $52.6 \%$ & 0.14 & 0.20 \\
\hline Refers to another professional & $65.9 \%$ & 0.01 & 0.17 \\
\hline Prescribes medication without indication & $10.4 \%$ & 0.09 & -0.03 \\
\hline \multicolumn{4}{|l|}{ Changing or initiating new medication } \\
\hline Informs about severe yet rare side effects & $72.9 \%$ & -0.10 & 0.18 \\
\hline Records that explained about side effects & $74.2 \%$ & 0.06 & 0.08 \\
\hline Informs of increased risk of suicidality & $47.3 \%$ & -0.01 & $0.23 \ddagger$ \\
\hline \multicolumn{4}{|l|}{ Pregnant patients } \\
\hline Avoids medication altogether & $46.8 \%$ & 0.05 & $0.39 \dagger$ \\
\hline Prescribes a smaller dosage & $45.6 \%$ & $0.27 \dagger$ & 0.05 \\
\hline \multicolumn{4}{|l|}{ Elderly patients } \\
\hline Informs of cerebrovascular diseases risk & $55.4 \%$ & -0.06 & 0.18 \\
\hline Prescribes a smaller dosage & $91.9 \%$ & $0.23 \dagger$ & 0.01 \\
\hline
\end{tabular}

psychiatrists have performed at least one of the four actions within the past month. ${ }^{13}$ Together with our study, these results are surprising, especially in light of previous reports asserting that psychiatry is a low-risk specialty. ${ }^{9}$ A recent study portrayed psychiatry as responsible for only $1 \%$ of compensations paid during the period of the study (2005-2014), with the lowest risk of recurrence of lawsuits. ${ }^{14}$ Nevertheless, Jena and colleagues ${ }^{9}$ reported an annual probability of $2.6 \%$ for psychiatrists being sued in the USA. Data also show that the proportion of physicians facing malpractice claims in low-risk specialties is about $36 \%$ by age 45 , and rises up to $75 \%$ at age 65 .

Another interesting finding was the tendency of younger psychiatrists to report defensive behaviours and practise defensive medicine (table 2), despite malpractice 
typically characterising older psychiatrists. MartinFumadó et $a l^{12}$ reported that, among Spanish doctors, the mean time from specialisation to motivating a claim was 12 years. Similarly, Reich et $a l^{10}$ reported that the risk of disciplinary action increased with the years of practice. This recognition of defensive medical practice among young doctors may be unique to psychiatry, as studies of defensive medicine in other specialties failed to show correlation with age. ${ }^{8}$ In the USA, a study regarding defensive medicine among high-risk specialist physicians showed that being in practice for over 30 years is a risk factor for practising defensive medicine. $^{2}$ Regarding psychiatry specifically, Passmore and Leung ${ }^{13}$ demonstrated that there is a higher propensity of junior trainees to admit patients to the hospital and to place patients on higher levels of observation than is necessary. A US study found that walk-in psychiatric patients are more likely to be admitted if treated by a less experienced psychiatrist (first or second year residents) compared with more experienced staff (third year residents and attending physicians). ${ }^{15}$

We did not find any gender differences in the acknowledgement of defensive practice; however, in treating suicidal patients, female doctors consulted more often with a senior psychiatrist than male doctors, and were also significantly more prone to refer to another mental health professional. This finding is noteworthy, especially in the light of a recent review that found that male doctors have nearly 2.5 times the odds of medicolegal actions compared with female doctors. ${ }^{16}$ Studdert et $a l^{14}$ reported that $82 \%$ of paid malpractice claims involved male physicians. It is noteworthy that the only gender differences in defensive practices were items related to seeking support from seniors or colleagues. This might reflect differences in gender attitudes in the practice of the profession more than defensive medicine per se, but there is a lack of literature in the field; thus, more research is required.

Beyond describing the scope of the phenomena of DP, we aimed to understand how one's awareness of practising defensive medicine was related to actually applying defensive behaviours (table 3). We considered the psychiatrist's answer to the question 'Do you practice defensive medicine?' as evidence of conscious practice of defensive medicine, as previous studies have done. ${ }^{17}$ However, reporting specific behaviours in different scenarios is not necessarily conscious or unconscious behaviour. We aimed to ascertain conscious versus unconscious behaviour by calculating the correlation between the answer to the previous question and selfreports of defensive practice behaviours in the four clinical scenarios. We assumed that a positive correlation between the self-acknowledgement of defensive practices and any specific behaviours (eg, increasing follow-up with suicidal patients) is good evidence that participants are conscious of practising defensive medicine (the more they admit defensive medicine, the more they increase follow-up). Conversely, no correlation implicates that they do not consider that behaviour as practising defensive medicine, for example, prescribing medication without indication to suicidal patients is apparently an unconscious defensive practice because it was not associated with self-acknowledgement of defensive medicine.

As expected, psychiatrists who were directly involved in malpractice claims were more prone to acknowledge defensive practice, as seen in other studies of defensive medicine in psychiatry ${ }^{13}$ and other medical specialties. ${ }^{3}$ When treating a suicidal patient, most physicians reported practising defensive behaviours on the questionnaire, except for prescribing medication without indication. Interestingly, only two items, 'advising hospitalisation even if unwarranted' and 'increased frequency of follow-up even if not necessary', were significantly correlated with acknowledgement of practising defensive medicine and higher levels of anxiety concerning malpractice claims. Psychiatrists cannot always predict or prevent patient suicide, even if they provide the best medical care possible. ${ }^{18}$ Nonetheless, the consequences of not preventing such an act hold a tremendous risk for malpractice liability. ${ }^{19}$ This inherently affects the considerations and treatment decisions made by the treating psychiatrist, who mostly uses 'positive' defensive medicine and assurance behaviours. Paradoxically, a referral to unnecessary hospitalisation can lead to reports about improper detention, one of the main reasons for lawsuits in this field. ${ }^{10}$ This again raises the question whether defensive medicine is effective in preventing the physician's malpractice liability. Moreover, only these two defensive behaviours were recognised as defensive medicine and not, for example, the referral of the suicidal patient to another professional. This finding led us to question to what extent psychiatrists are aware of their defensive practices.

When examining the relationship between acknowledgement of defensive practice and treatment of pregnant women, we found that psychiatrists prescribe smaller dosages of medication than is customary. They may not recognise that they are practising defensive medicine when avoiding prescribing proper dosages to these patients. However, psychiatrists who experience more anxiety about malpractice claims avoid giving pregnant women medication altogether, implying that this behaviour is indeed related to defensive medicine. This practice raises special concerns as it is known that untreated depression or anxiety during pregnancy may negatively impact the mother and fetus, and residual depression due to inefficient dosage of psychotropic treatment may result in dual exposures for the fetus to medication and untreated depression. ${ }^{20}$

Prescribing smaller drug dosages than customary was also evident in the treatment of elderly patients. Certified psychiatrists, more often than residents, attributed this to the propensity of antipsychotic drugs to cause cerebrovascular diseases. This practice correlated with acknowledgement of defensive medicine, but not with higher levels of anxiety. These reported prescribing 
habits are in accordance with the FDA black box warning and guidelines from 2005 and may not represent malpractice concerns, but rather a more clinical standpoint in treating this population.

One alarming finding is that $10.4 \%$ of participants in the survey stated that they prescribed medication without indication. Since it has no significant correlation with acknowledgement of defensive practice or anxiety, we concluded that this may be an expression of unconscious defensive behaviour, though there may be other, patient-specific as well as doctor-specific, factors that influence whether or not to prescribe medication. Bradley $^{21}$ demonstrated in his study that $44.3 \%$ of doctors who reported that they were prescribing medication in order to preserve the doctor-patient relationship experienced discomfort. This was described in terms of avoiding litigation or reports, and also as avoiding damage to the doctor-patient relationship, avoiding conflict and 'keeping the peace'.

Finally, the study showed that among participants of the study, malpractice claims raised distressful feelings suggesting that they are the 'second victims', meaning that they, the caregivers, may be extremely distressed by the mistakes they have committed. ${ }^{22}$ Furthermore, the caregiver subjected to legal proceedings may experience the 'clinical judicial syndrome' (CJS) that comprises a series of physical, psychological and behavioural symptoms. ${ }^{23}$ The associations between levels of anxiety or anger after malpractice reports among study participants, and measures of defensive behaviours and defensive practices are in line with Pellino and Pellino's ${ }^{24}$ assertion that defensive medicine, the concept of 'second victim' and CJS are indeed an intertwined phenomena.

\section{Limitations}

The survey was voluntary; therefore, it is possible that physicians who agreed to participate were more prone to acknowledge practising defensive medicine, thus biasing the results. Furthermore, physicians were recruited among attendants to a psychiatric congress, which may limit the generalisation of the findings. This study described psychiatrists' perceptions of defensive medicine and not objective data that may describe this phenomenon. Self-reports of defensive medicine may be biased, and may lead physicians to overstate the frequency of performing defensive medicine. Objective methods for measuring defensive medicine are extremely difficult to employ. ${ }^{13}$ It is often difficult to identify the difference between liability-related motivation and other factors that influence clinical decision-making. For example, in this study, practices that could be viewed as defensive medicine, such as initiate contact with the family of a suicidal patient' and 'inform of severe yet rare side effects of new drug treatment', characterised a high percentage of doctors, but were not correlated with defensive medicine or anxiety levels. These clinical decisions might reflect the policy of the institution where the physician works, the personal attitude of the physician, a less patriarchal standpoint that sees the patient's right to decide about their treatment and more.

There are no available data on the respondent's annual incomes and malpractice premiums. In Israel, a premium is paid by the employer as part of the national work contracts with the Israeli Medical Association. Thus, since this is not 'out-of-pocket money', both these factors probably do not influence the daily practice of defensive medicine in our cohort.

\section{CONCLUSIONS}

Defensive medicine is well established in routine clinical psychiatry, despite this specialty having a low risk for malpractice lawsuits. Coping with the defensive medicine is a challenging task. Although there are several suggested strategies, evidence is lacking and there is not one efficient solution to resolve this issue. ${ }^{25}$ Any solution should include changes in the physician's, as well as the patient's, perspective and behaviour. This may include giving more information to the public regarding the recommended care and relevant diagnostic and treatment options in clinical situations prone to defensive medicine. Also, developing and applying clinical practice guidelines targeting risky clinical situations may aid doctors when faced with difficult situations. Finally, making reforms in the liability and compensation systems available today may be a way to preserve the beneficial effects of defensive medicine while diminishing its hazardous effects. Further studies are necessary to determine if the putative effect of defensive medicine impedes high quality clinical psychiatric care of patients, to examine the economic burden of DP on healthcare providers and explore different strategies to cope with this troubling phenomenon.

\section{Author affiliations}

${ }^{1}$ Department of Psychiatry, Hadassah Hebrew University Medical Center, Jerusalem, Israel

${ }^{2}$ Department of Health Systems Management, Faculty of Health Sciences, Ben-Gurion University of the Negev, Beer-Sheva, Israel

${ }^{3}$ Department of Psychology, Hebrew University, Jerusalem, Israel

Contributors All authors contributed extensively to the work presented in this paper. IR and IP designed the study, collected data and wrote the manuscript. HR conceived the study and edited the prepared manuscript. OB supervised the data collection and analysis and edited the manuscript. LC performed the statistical analysis, interpreted the data and wrote the manuscript.

Funding This research received no specific grant from any funding agency in the public, commercial or not-for-profit sectors.

\section{Competing interests None declared.}

Provenance and peer review Not commissioned; externally peer reviewed.

Data sharing statement Supporting data are available on request. Please contact the corresponding author reuveni@hadassah.org.il

Open Access This is an Open Access article distributed in accordance with the Creative Commons Attribution Non Commercial (CC BY-NC 4.0) license, which permits others to distribute, remix, adapt, build upon this work noncommercially, and license their derivative works on different terms, provided the original work is properly cited and the use is non-commercial. See: http:// creativecommons.org/licenses/by-nc/4.0/ 


\section{REFERENCES}

1. Anderson RE. Billions for defense: the pervasive nature of defensive medicine. Arch Intern Med 1999;159:2399-402.

2. Studdert DM, Mello MM, Sage WM, et al. Defensive medicine among high-risk specialist physicians in a volatile malpractice environment. JAMA 2005;293:2609-17.

3. Asher E, Greenberg-Dotan S, Halevy J, et al. Defensive medicine in Israel-a nationwide survey. PLOS ONE 2012;7:e42613.

4. Simon RI. Defensive psychiatry and the disruption of treatment boundaries. Isr J Psychiatry Relat Sci 2000;37:124-31.

5. Kessler DP, Mcclellan M. Do doctors practice defensive medicine? Q J Econ 1996;111:353-90.

6. Mello MM, Chandra A, Gawande AA, et al. National costs of the medical liability system. Health Aff 2010;29:1569-77.

7. Hermer LD, Brody H. Defensive medicine, cost containment, and reform. J Gen Intern Med 2010;25:470-3.

8. Asher E, Dvir S, Seidman DS, et al. Defensive medicine among obstetricians and gynecologists in tertiary hospitals. PLOS ONE 2013;8:e57108.

9. Jena $A B$, Seabury $S$, Lakdawalla $D$, et al. Malpractice risk according to physician specialty. N Engl J Med 2011;365:629-36.

10. Reich J, Schatzberg A. An empirical data comparison of regulatory agency and malpractice legal problems for psychiatrists. Ann Clin Psychiatry 2014;26:91-6.

11. Thompson JW, Boudreaux JM, Artecona J. Medical malpractice: Psychiatry. In: Payne-James J, Byard RW, eds. Encyclopedia of Forensic and legal medicine. 2nd edn. Cambridge, MA: Academic Press, 2016:484-8.

12. Martin-Fumadó C, Gómez-Durán EL, Rodríguez-Pazos M, et al. Medical professional liability in psychiatry. Actas Esp Psiquiatr 2015;43:205-12.

13. Passmore K, Leung WC. Defensive practice among psychiatrists: a questionnaire survey. Postgrad Med J 2002;78:671-3.
14. Studdert DM, Bismark MM, Mello MM, et al. Prevalence and characteristics of physicians prone to malpractice claims. $N$ Engl J Med 2016;374:354-62.

15. Meyerson AT, Moss JZ, Belville R, et al. Influence of experience on major clinical decision. Training implications. Arch Gen Psychiatry 1979;36:423-7.

16. Unwin $\mathrm{E}$, Woolf $\mathrm{K}$, Wadlow $\mathrm{C}$, et al. Sex differences in medico-legal action against doctors: a systematic review and meta-analysis. BMC Med 2015;13:172.

17. Silberstein E, Shir-Az O, Reuveni $\mathrm{H}$, et al. Defensive medicine among plastic and aesthetic surgeons in Israel. Aesthet Surg J 2016;36: NP299-304.

18. Sher L. Preventing suicide. QJM 2004;97:677-80.

19. Bleich A, Baruch Y, Hirschmann S, et al. Management of the suicidal patient in the era of defensive medicine: focus on suicide risk assessment and boundaries of responsibility. Isr Med Assoc J 2011;13:653-6.

20. Byatt N, Deligiannidis KM, Freeman MP. Antidepressant use in pregnancy: a critical review focused on risks and controversies. Acta Psychiatr Scand 2013;127:94-114.

21. Bradley CP. Factors which influence the decision whether or not to prescribe: the dilemma facing general practitioners. $\mathrm{Br} J$ Gen Pract 1992;42:454-8.

22. Wu AW. Medical error: the second victim. The doctor who makes the mistake needs help too. BMJ 2000;320:726-7.

23. Hurtado Hoyo $\mathrm{E}$, Gutiérrez Zaldívar $\mathrm{H}$, Iraola $\mathrm{N}$, et al. Síndrome Clínico Judicial. Rev Asoc Med Argent 2006;119:8-16.

24. Pellino IM, Pellino G. Consequences of defensive medicine, second victims, and clinical-judicial syndrome on surgeons' medical practice and on health service. Updates Surg 2015;67:331-7.

25. Sclar D, Housman M. Medical malpractice and physician liability: examining alternatives to defensive medicine. Harv Health Pol Rev 2003;4:75-84 